\title{
Supervisor practice when guiding therapists working with depression: the impact of supervisor and patient characteristics
}

\author{
Chloe Simpson-Southward ${ }^{1}$, Glenn Waller ${ }^{1}$ and Gillian Hardy ${ }^{2}$ \\ ${ }^{1}$ Department of Psychology, University of Sheffield, Sheffield S1 2LT, UK \\ ${ }^{2}$ Clinical Psychology Unit, Department of Psychology, University of Sheffield, Sheffield S1 2LT, UK
}

Received 13 October 2017; Accepted 1 June 2018

\begin{abstract}
Currently recommended psychotherapies for depression are not always delivered in a consistent manner. There is an assumption that the use of clinical supervision will ensure reliable treatment and patient recovery. However, there is limited research supporting this assumption. This study explored the role of supervision in the treatment of depression. In particular, it examined how supervisors' own characteristics and those of patients can influence the focus of supervision sessions. Clinical supervisors who worked with cognitive behavioural therapy (CBT) therapists treating depression cases were asked to indicate their supervision focus for three different patient vignettes. These vignettes varied in clinical complexity. Participants' intolerance to uncertainty and their self-esteem were also assessed. Supervisors tended to focus their supervisees on the use of evidence-based therapeutic techniques for both straightforward and complex cases. However, their approach was less evidencebased for diffuse cases. Three supervisory types emerged: an 'Alliance- and TechniqueFocused' group, a 'Case Management-Focused' group, and an 'Unfocused' group. Personal characteristics of the supervisors varied across the groups. The content of supervision sessions is influenced by factors from outside the therapy process. These factors might cause supervisors to avoid focusing on evidence-based aspects of therapy, thus feeding therapist drift. Suggestions are made for new supervision protocols that consider the supervisor's personal characteristics.
\end{abstract}

Key words: clinical supervision, depression, cognitive behavioural therapy, anxiety, evidence-based practice

\section{Introduction}

Depression is one of the most common mental health problems, estimated to affect approximately 350 million people around the world (Marcus et al., 2012). Affected people lose an average of 5.6 hours of productive work per week, making the illness the leading

Correspondence to Chloe Simpson-Southward, Department of Psychology, University of Sheffield, Sheffield, UK (email: crsimpson-southward1@ sheffield.ac.uk). 
cause of disability worldwide (Stewart et al., 2003; World Health Organisation, 2012). There are two core symptoms of depression - an extremely low mood, and decreased pleasure or interest in most activities. The symptoms combined can leave sufferers feeling that their only escape is suicide (Leahy et al., 2012). The impact of this illness on the sufferer's quality of life and the financial implications upon our society are clear. Therefore, the availability of effective treatments for depression is essential. While such psychological treatments do exist, they are not universally effective. Nor are they always delivered effectively or consistently (e.g. Wang et al., 2002). There is an assumption that supervision of therapists will ensure adequate, accurate delivery of psychological therapies (Lambert and Ogles, 1997; Milne and James, 2000; Wampold and Holloway, 1997). However, that assumption requires support. This study will consider the role of supervision in ensuring that such treatments for depression are delivered in a consistent manner. In particular, it will examine if supervisors' own characteristics and those of patients with depression combine to influence the recommendations that supervisors give to their supervisees.

Several randomized controlled trials (RCTs) have found cognitive behavioural therapy (CBT) to be efficacious for depression (e.g. Butler et al., 2006; Gloaguen et al., 1998). For this reason, National Institute for Health and Care Excellence (NICE) guidelines recommend the use of CBT, with or without anti-depressant medication, for all forms of depression (NICE, 2011). Unfortunately, clinical improvement and recovery rates for patients with depression in routine clinical settings are not always as high as in RCTs. Those treated in RCT settings have been found to have almost three times as much symptom improvement as those treated in an outpatient setting (Gibbons et al., 2013).

While RCTs are accepted as the 'gold standard' for intervention research, they include procedures that are often very different to the delivery of the interventions in routine practice (Gibbons et al., 2010). It is possible that these differences are the cause of the discrepancy between patient outcomes in the two settings. A core difference between the RCT and routine practice is the patient samples. Patients must often meet very strict criteria for inclusion in RCTs, but this is not the case in a routine setting (Kazdin, 2008). However, this is not a complete explanation, as patient complexity does not fully explain differences in outcome between RCTs and routine practice (e.g. Gibbons et al., 2013; Weisz et al., 2006). A second difference between RCTs and usual clinical care is the therapists themselves, and whether or not they adhere to the evidence-based protocols. There is evidence that therapists routinely diverge from evidence-based methods - a phenomenon known as therapist drift (Waller, 2009). However, such drift occurs less in the context of a closely monitored intervention, as shown by Gibbons et al. (2013). Therefore, it is important to understand why this variation in practice occurs between controlled and routine settings.

It can be suggested that part of the reason for clinicians' less consistent and effective performance in routine settings might lie in the content and process of clinical supervision. The parallel processes between supervision and therapy might mean that the effect of the supervisor in supervision can, ultimately, have an effect upon the patient in therapy (Tracey et al., 2012). Although supervision in RCT settings has not been directly compared with supervision in clinical settings, RCT supervision seems to differ from supervision in clinical practice. RCT clinicians receive closer, more structured supervision (Gibbons et al., 2013; Roth et al., 2010; Tracey et al., 2012). Roth et al. (2010) found that the majority of clinical trials required a minimum of weekly supervision, whereas professional bodies in clinical settings require a minimum of monthly supervision (e.g. British Association for Behavioural 
and Cognitive Psychotherapies, 2012; British Association for Counselling and Psychotherapy, 2016). Therefore, it is possible that the quantity or quality of supervision contributes to differences in patient outcomes between RCTs and clinical settings.

There are several proposed models of supervision, including: developmental models (Stoltenberg and Delworth, 1987; van Ooijen, 2000; Worthington, 1987); competency-based models (Bernard and Goodyear, 2004; Mead, 1990); and process models (Hawkins and Shohet, 1989; van Ooijen, 2000). However, there is little empirical evidence showing which model is best, or even that supervision results in better client outcomes (Bambling et al., 2006; Ellis and Ladany, 1997; Kilminster and Jolly, 2001; Milne and James, 2000). Thus, it cannot be assumed that supervision in routine settings is adequate to keep the therapy on track in the way that the stricter conditions in RCTs can ensure. For example, the objectivity of clinical supervision is questionable, given evidence that supervisors of therapists substantially over-estimate the ability of their supervisees (Dennhag et al., 2012). This over-estimation makes it likely that supervisors will be less demanding than they should be in routine settings. Therefore, it is possible that supervisors' own practices could permit supervisees to stray from effective practice. In other words, supervisor drift could permit or drive therapist drift.

While the emotional, behavioural and cognitive factors that are associated with therapist drift are increasingly well understood (e.g. anxiety, safety behaviours, dismissal of manuals; Lilenfeld et al., 2013; Waller, 2009), little is known about the reasons why supervisors might or might not drift in this way. Therefore, this study will explore, experimentally, a key element in what influences supervisors of clinicians working with depression - the nature of the clinical case being presented - and how that element interacts with the supervisor's own characteristics. This study has two aims. First, it will investigate how the content of supervision sessions varies depending on the clinical case that is presented in the supervision. Second, it will determine if those patterns of supervisor focus fall into natural groupings (e.g. do clinicians report focusing on therapeutic alliance or evidence-based techniques, but not both?), and if those patterns are related to supervisors' other characteristics. Specifically, this will consider those characteristics that have previously been linked to therapist drift, e.g. tolerance of uncertainty (Turner et al., 2014), age and clinical experience (Waller et al., 2012).

\section{Method}

\section{Design}

This was a within-subject, survey-based, experimental design, with all participants undertaking all conditions. The independent variable was the variation in patient vignettes, and the dependent variable was supervisor reaction (guidance given to supervisees working with patients with depression).

\section{Participants}

The participants were a sample of 42 clinical supervisors, guiding clinicians in the delivery of CBT for depression. Although all worked as clinical supervisors, only 27 were accredited supervisors $(64.3 \%)$. The mean age of the group was 50.2 years $(S D=10.6$, range $=35-67)$, and $61.9 \%$ were female. The supervisors were members of organizations that were part of the European Association for Behavioural and Cognitive Therapies. They were from eight 
different countries across Europe, with the largest number working in the UK (47\%) and the second largest in the Netherlands (16.7\%). The mean amount of time they had been using CBT was 15.9 years $(S D=8.90$, range $=0-38)$. The background professions of the supervisors were: clinical psychologists $(n=20)$, nurses $(n=5)$, counselling psychologists $(n=3)$, social workers $(n=2)$, occupational therapists $(n=2)$, psychiatrists $(n=2)$, high intensity Improving Access to Psychological Therapies workers (IAPT; $n=2$ ), psychotherapists $(n=2)$, a health clinical psychologist $(n=1)$, a psychotherapist and medical doctor $(n=1)$, and a mental health practitioner $(n=1)$. One supervisor gave no background profession.

\section{Ethics}

This research was approved by the University of Sheffield's Department of Psychology Research Ethics Committee.

\section{Measures and procedure}

All participants were sent an email containing a link to an online questionnaire (adapted from Simpson-Southward et al., 2016), hosted by the website Qualtrics. Participants indicated consent and provided demographic information. Three case vignettes were then presented, each relating to individuals with depression with whom their supervisees would be working. The vignettes were based on the clinical experience of two of the authors (G.H. and G.W.), to ensure that it represented a realistic scenario that the supervisor would be likely to attend to and might respond to. These were presented in random order. The vignettes varied in terms of patients' clinical severity - one straightforward case of depression, one diffuse case, and one complex case (see Appendix 1 for full vignettes). Each was relatively brief, to ensure that the supervisor reaction to the nature of the case was not related to or obscured by superfluous information.

Following each vignette, the participant was asked what they would focus on in supervision for each case. Focus was measured using sliding scales, ranging from 0 ('I would not focus on this') to 100 ('I would focus entirely on this'). The questions referred to three general areas of supervision focus: therapeutic technique, therapeutic alliance, and case management issues. These areas of focus were based on the three main functions of supervision often described in the literature. Proctor (1988) refers to these functions as 'formative' (education and development of the supervisee), 'restorative' (emotional aspects of work), and 'normative' (managerial and ethical responsibilities). The same functions are referred to as 'educational', 'supportive' and 'managerial' by Kadushin (1976). Further detail was requested to clarify which specific supervision methods the supervisors would focus on. Methods relating to the therapeutic alliance were: developing and maintaining the therapeutic bond with the patient; agreement on therapy tasks; and agreement on therapy goals. Those relating to the therapeutic techniques were: reviewing depression levels; CBT model education; agenda setting; Socratic questioning; linking cognitions, emotions and behaviour; recording of negative automatic thoughts; clarifying dysfunctional assumptions; developing alternative hypotheses; behavioural activation; mindfulness; eye movement desensitization and reprocessing; responding to patient feedback; discussion of thought records; reviewing homework tasks; behavioural experiments; cognitive rehearsal; assertiveness training; use of reattribution; and relapse prevention techniques. Case management issues covered: risk focus; 
focus on the patient's capacity to use and benefit from treatment; focus on the patient's week; and encouragement of the therapist to remain on track.

Participants were then asked to fill out two measures. These measures were presented after the vignettes to reduce demand characteristics. Participants' reactions to uncertainty, ambiguous situations and the future were measured using the 12-item version of the Intolerance of Uncertainty Scale (IUS; Carleton et al., 2007). The IUS measures two aspects of intolerance of uncertainty - 'prospective anxiety' (fear and anxiety relating to future events), and 'inhibitory anxiety' (uncertainty that inhibits action). The IUS has high internal consistency (full scale $\alpha=.91$, prospective anxiety $\alpha=.85$, and inhibitory anxiety $\alpha=.85$ ). Finally, participants' self-esteem was measured using the Rosenberg Self-Esteem Scale (RSE; Rosenberg, 1965). The RSE measures both positive and negative views of the self, and has well-established psychometric properties ( $\alpha$ ranging from .72 to .88; Gray-Little et al., 1997). Due to a technical error, scores were collected for only nine of the ten items, so the score was prorated.

\section{Data analysis}

To address the first aim, a repeated measures analysis of variance (ANOVA) was used to assess the reactions of the supervisors to each vignette. The within-subject factor was the different clinical condition (presentation type), and the dependent variables were the levels of focus on each supervision topic. To address the second aim, two-step cluster analysis was used to identify naturally occurring supervisor 'types', and these were validated against other measures using one-way ANOVAs and chi-squared tests.

\section{Results}

\section{'Supervision focus' scale reliability}

The Cronbach's alphas of the three scales were (in the order 'straightforward', 'diffuse' and 'complex' each time): 0.701, 0.511 and 0.642 for therapeutic alliance; $0.893,0.908$ and 0.878 for therapeutic techniques; and $0.641,0.583$ and 0.742 for case management. It is likely that the low alpha levels for some of the therapeutic alliance and case management scores are because the number of items in each is too low to allow for reliable calculation of Cronbach's alpha. However, the alphas for the therapeutic techniques scale suggest that the items reflect a single construct rather than containing divergent techniques.

\section{Supervision focus for different clinical conditions}

Addressing the first aim, overall patterns of supervision focus (alliance, CBT techniques and case management issues) are shown in Table 1 for each case presentation. The overall pattern was that the supervisors stated that they would focus their supervisees most on techniques and least on case management issues, with the level of focus on the alliance lying between those two. The ANOVAs showed that the type of case made no significant difference to the level of focus on the alliance or case management issues (all $p>.05$ ). However, there was a significant difference in the level of focus on evidence-based techniques, which the supervisors reported stressing least when the case presentation was relatively diffuse $(F(2,84)=5.19, p=.008)$. 
Table 1. ANOVAs showing differences in overall supervision focus per case

\begin{tabular}{lllllllc}
\hline & \multicolumn{3}{c}{ Patient type } & & \multicolumn{3}{c}{ ANOVA } \\
\cline { 2 - 3 } \cline { 6 - 8 } & $\begin{array}{l}\text { Straight } \\
\text { forward (1) }\end{array}$ & Diffuse (2) & Complex (3) & $F$ & $P$ & $\begin{array}{l}\text { Multiple } \\
\text { comparisons }\end{array}$ \\
\hline Alliance & $50.0(25.9)$ & $46.4(24.2)$ & $54.9(27.1)$ & & 2.92 & .071 & - \\
Techniques & $70.0(22.0)$ & $58.6(27.0)$ & $68.6(24.7)$ & & 5.19 & .008 & $1=3>2$ \\
Case-Management & $35.1(24.6)$ & $44.6(28.7)$ & $42.6(23.7)$ & & 2.71 & .073 & - \\
\hline
\end{tabular}

\section{Supervision styles when delivering CBT for depression}

The second aim was to find out whether there are different natural patterns of supervisory practice. Using the supervisors' overall scores on the degree to which they would focus on different therapy elements (alliance, techniques, case management), two-step cluster analysis provided a three-cluster solution. The first cluster (33.3\% of the sample) were supervisors who indicated that they spend little time on any of the aspects of supervision. Therefore, they are referred to as 'Unfocused'. The second cluster (23.8\% of the sample) consisted of supervisors who mainly focused on topics of supervision other than alliance and technique. They are referred to as 'Case Management-Focused'. The final, and largest, cluster $(42.9 \%$ of the sample) consisted of supervisors who focused on both the therapeutic alliance and therapeutic techniques. They are therefore labelled 'Alliance- and Technique-Focused'.

Clinical validation of the clusters. Using one-way ANOVAs, the three clusters were compared on participant characteristics (Table 2). Relative to the Unfocused group, the individuals who were Case Management-Focused had been qualified $(F(2,39)=6.11$, $p=.005)$, accredited $(F(2,32)=5.72, p=.008)$ and using $\operatorname{CBT}(F(2,39)=3.50, p=.040)$ for longer. In contrast, compared with the Alliance- and Technique-Focused group, the Case Management-Focused group had higher levels of prospective anxiety $(F(2,38)=5.83$, $p=.006)$ and worked less with depression $(F(2,39)=3.33, p=.046)$.

The only categorical characteristic found to be associated with the clusters was supervisor accreditation $\left(\chi^{2}=13.83\right.$ (d.f. $\left.\left.=2\right), p=.001\right)$. In the 'Unfocused' cluster, $28.6 \%$ were accredited, compared with $100 \%$ of the 'Case Management-Focused' cluster and $72.2 \%$ of the 'Alliance- and Technique-Focused' group. Categorical characteristics found not to be associated with the clusters were gender; country of training trained; current country of residence; background profession; use of treatment manuals; and therapist accreditation.

\section{Discussion}

This study explored the focus of CBT supervision for depression cases, comparing patterns of guidance given to clinicians working with patients with different levels of clinical complexity. Overall, it is reassuring that supervisors tended to focus on evidence-based techniques, especially for straightforward and complex depression cases. However, for relatively diffuse cases, supervisors reported taking a less evidence-based approach.

Three clear supervisory types emerged from the sample: an Alliance- and TechniqueFocused group, a Case Management-Focused group, and an Unfocused group. An important 
Table 2. One-way ANOVAs comparing the three supervisor clusters on supervisor characteristics

\begin{tabular}{|c|c|c|c|c|c|c|c|}
\hline & \multicolumn{3}{|c|}{ Supervisor type } & \multicolumn{4}{|c|}{ ANOVA } \\
\hline & Unfocused (1) & $\begin{array}{l}\text { Case } \\
\text { Management- } \\
\text { Focused (2) }\end{array}$ & $\begin{array}{l}\text { Alliance- and } \\
\text { Technique- } \\
\text { Focused (3) }\end{array}$ & $n$ & $F$ & $p$ & $\begin{array}{l}\text { Multiple } \\
\text { comparisons }\end{array}$ \\
\hline Age & $48.0(11.8)$ & $53.6(9.62)$ & $49.9(10.3)$ & 42 & .811 & .452 & - \\
\hline $\begin{array}{l}\text { No. of patients with a primary } \\
\text { diagnosis of depression }\end{array}$ & $26.4(20.1)$ & $16.5(9.73)$ & $36.2(23.0)$ & 42 & 3.33 & .046 & $3>2$ \\
\hline Time qualified & $11.7(7.00)$ & $24.7(8.08)$ & $17.6(10.6)$ & 41 & 6.11 & .005 & $2>1$ \\
\hline Time using CBT & $12.0(8.04)$ & $21.2(9.22)$ & $15.9(8.22)$ & 42 & 3.50 & .040 & $2>1$ \\
\hline $\begin{array}{l}\text { Time accredited as therapist } \\
\text { (years) }\end{array}$ & $8.69(5.35)$ & $22.6(11.5)$ & $13.0(9.71)$ & 35 & 5.72 & .008 & $2>1$ \\
\hline $\begin{array}{l}\text { Time accredited as supervisor } \\
\text { (years) }\end{array}$ & $4.0(1.41)$ & $15.5(11.1)$ & $9.51(9.36)$ & 27 & 2.36 & .116 & - \\
\hline $\begin{array}{l}\text { Intolerance of uncertainty - } \\
\text { prospective }\end{array}$ & $2.30(.680)$ & $2.73(.367)$ & $1.99(.463)$ & 41 & 5.83 & .006 & $2>3$ \\
\hline $\begin{array}{l}\text { Intolerance of uncertainty - } \\
\text { inhibitory }\end{array}$ & $1.37(.414)$ & $1.84(.467)$ & $1.42(.837)$ & 41 & 1.68 & .199 & - \\
\hline Rosenberg Self-Esteem scale & $22.6(4.37)$ & $22.2(3.39)$ & $25.3(2.87)$ & 42 & 3.36 & .045 & - \\
\hline
\end{tabular}


point to note is that there was no distinction between supervisors who encouraged a focus on CBT techniques or the alliance - if the supervisor addressed one, they addressed both (albeit they stressed the use of techniques to a greater degree). Perhaps more surprising was the number of supervisors whose guidance for supervisees seemed to lack any of these foci, regardless of the nature of the case (at least within the domain of depression). These three patterns of clinical supervisory practice were related to the characteristics of the supervisors themselves. Those who were more likely to focus their supervisees on case management issues were more likely to have anxiety surrounding future events but to have also been practising for longer than others. In contrast, those who focused on guiding both alliance and technique in supervision also tended to be those who had higher self-esteem.

The three supervisor types that have emerged from these data seem to be partially reflected in established supervision models. However, while most models tend to focus on one specific aspect of the supervision (Bernard and Goodyear, 2004; Hawkins and Shohet, 1989; Mead, 1990; van Ooijen, 2000), that was not the case here. The largest group of supervisors (Alliance- and Technique-Focused) combines features of competency-based models focusing on techniques (Bernard and Goodyear, 2004; Mead, 1990) and process models focusing on relationship dynamics (Hawkins and Shohet, 1989; van Ooijen, 2000). Thus, supervision models might need to be developed to allow for this dual focus in everyday practice, rather than being presented as alternatives. A new supervision model might take evidence-based aspects of other models and combine them for a more integrative model. Such a model should also take into account the characteristics of the supervisors themselves. Based on the current study, it is clear that supervisors need to evaluate their own characteristics, as well as those of their supervisees and patients.

The finding that supervisor characteristics are associated with their supervisory practice needs consideration. The fact that supervisors with higher levels of prospective anxiety are likely to encourage supervisees to focus on case management (e.g. monitoring risk; exploring the patient's week) is compatible with the finding that more anxious therapists avoid the use of core CBT techniques in therapy (e.g. Meyer et al., 2014; Waller et al., 2012). It is also possible that supervisors' fear over future events leads them to focus on patient safety to the exclusion of more change-oriented methods. Similarly, the higher self-esteem of those who focus on the alliance and techniques is compatible with the finding that clinicians with higher self-esteem are more likely to use treatment manuals (Waller et al., 2013). This result might also be related to the finding that high supervisor self-acceptance and self-efficacy positively affects trainees' outcomes (Moldovan and David, 2013). What is possibly more unexpected is the tendency for more experienced supervisors to focus their supervisees more on case management and less on alliance and techniques, though it could be argued that this is a simple example of supervisory drift with time.

Although supervision is usually thought to keep therapists on track (Bernard and Goodyear, 2004; Care Quality Commission, 2013; van Ooijen, 2000), the present findings indicate that this assumption is subject to doubt, as supervisors themselves are influenced by similar factors to therapists, causing them to drift off track. Given the reliance that many professions and therapies place on supervision, it is possible that supervisory drift accounts in part for therapist drift, and hence for differences in patient outcomes across settings (Gibbons et al., 2013). In particular, the demands placed on supervisors in RCT conditions are usually more regulated (Roth et al., 2010; Tracey et al., 2012). It might be argued that routine clinical practice would be augmented by the establishment of protocols for supervision of those clinicians. 
Those protocols might explicitly address the characteristics of supervisors and how those characteristics could result in therapist drift. Similarly, it can be suggested that supervisors' worry around future events and self-esteem levels might be addressed as part of training and continuing professional development, as has been recommended for clinicians delivering exposure-based therapy (e.g. Farrell et al., 2013).

For such training to be effective, supervisor tolerance of uncertainty and self-esteem should be explored further. A key issue is that this study has considered the potential role of prospective and inhibitory anxiety, and self-esteem within normal, non-clinical limits. Future research might focus on whether these patterns of supervisor behaviour are exacerbated when one focuses specifically on supervisors with levels of anxiety and self-esteem that are more representative of clinical groups. The findings of the current study might be picking up different forms of anxiety, such as state anxiety, as well as trait anxiety (due to the order in which the study materials were presented). Future research should, therefore, look to tease out the types of anxiety that supervisors are experiencing.

The findings in this study relate to the supervision of clinicians working with depression. Further research will need to consider the impact of supervisor characteristics on how they guide treatment for other disorders. Future research into the impact of supervisors' characteristics on the recommendations that they make will need to cover other disorders. It will also be important that further research into supervisor practice in depression and other disorders considers the triadic relationship involved. This study has considered the impact and relationship of patient and supervisor characteristics. However, that does not allow for the intermediary role of the clinician being supervised. An important development of this research will be considering how supervisee and supervisor characteristics combine to influence the therapy being delivered. For example, is there an additive effect, such that having a supervisor and clinician who are both alliance- and technique-focused will have more positive results, while having a supervisor and clinician with contrasting approaches might lessen the impact of the therapy? And will having a supervisor and clinician who are both unable to tolerate uncertainty be even less beneficial for the patient, or is one of the two being more tolerant sufficient for the patient to benefit? Similarly, can a less experienced clinician retain focus on alliance and technique, even when a more experienced supervisor is directing therapy away from that focus? These are questions that can initially be addressed using vignette studies of this sort, but that would benefit from naturalistic, observational studies that relate real-life supervisory and clinical practice to patient outcomes and experiences.

The use of naturalistic studies will enhance this area of research, as there are some limitations to questionnaire research. Due to the need to keep questionnaires concise, there might not have been enough information given in this study to ensure that the supervisory content items did not confuse the participants. Although these items were outlined under specific categories (e.g. 'therapeutic techniques'), any confusion might have caused some overlap between the categories. In addition, the imbalance of items between the categories could have caused some response bias towards selecting items from the 'therapeutic techniques' category. Observational studies would alleviate such problems.

The current study only provides a snapshot into supervisory intentions. Due to time restrictions and the need to prioritize certain patients in clinical settings, supervisors might only be provided with a small amount of detail about some patients, similar to the vignettes used in this study. However, this study has an analogue nature. In many real-life cases, the supervisor will have more information to work with - perhaps including video or audio 
recordings of the therapy sessions. Future research could benefit from the use of such recordings. These provide supervisors with a much richer source of information, thus allowing researchers to take a much deeper look into supervisory intentions.

\section{Main points}

(1) There is an assumption that clinical supervision keeps therapy on track and helps deliver positive patient outcomes; however, there is little evidence to support this.

(2) The present study found that supervisors tended to focus their supervisees on the use of evidence-based therapeutic techniques for both straightforward and complex cases of depression.

(3) Supervisors' approach to diffuse depression cases was less evidence-based.

(4) Three supervisory 'types' were found and which group the supervisors fell into was related to their personal characteristics.

(5) It is possible that supervisors drift from evidence-based practice in the same way that has previously been found with therapists.

\section{Ethical statement}

This research was approved by the University of Sheffield's Department of Psychology Research Ethics Committee.

\section{Conflicts of interest}

Chloe Simpson-Southward, Glenn Waller, and Gillian Hardy have no conflicts of interest with respect to this publication.

\section{Financial support}

C.S.S. is supported by a grant from the Howard Morton Trust. G.W. and G.H. do not have specific grants covering this research.

\section{Recommended follow-up reading}

Dennhag I, Gibbons MBC, Barber JP, Gallop R, Crits-Christoph P (2012). Do supervisors and independent judges agree on evaluations of therapist adherence and competence in the treatment of cocaine dependence? Psychotherapy Research 22, 720-730.

Gibbons CR, Stirman SW, DeRubeis RJ, Newman CF, Beck AT (2013). Research setting versus clinic setting: which produces better outcomes in cognitive therapy for depression? Cognitive Therapy Research 37, 605-612.

Lilenfeld SO, Ritschel LA, Lynn SJ, Cautin RL, Latzman RD (2013). Why many clinical psychologists are resistant to evidence-based practice: root causes and constructive remedies. Clinical Psychology Review 33, 883-900.

Simpson-Southward C, Waller G, Hardy G (2016). Supervision for treatment of depression: an experimental study of the role of therapist gender and anxiety. Behaviour Research and Therapy 77, 17-22.

Watkins CE (1997) Handbook of Psychotherapy Supervision. New York, NY: Wiley 


\section{References}

Bambling M, King R, Raue P, Schweitzer R, Lambert W (2006). Clinical supervision: its influence on client-rated working alliance and client symptom reduction in the brief treatment of major depression. Psychotherapy Research 16, 317-331.

Bernard JM, Goodyear RK (2004). Fundamentals of Clinical Supervision. Boston, MA: Pearson Education.

British Association for Behavioural and Cognitive Psychotherapies (2012). British Association for Behavioural and Cognitive Psychotherapies minimum training standards for the practice of cognitive behavioural therapy (CBT). Available at: http://www.babcp.com/Accreditation/ Minimum-Training-Standards.aspx (accessed 31 January 2018).

British Association for Counselling and Psychotherapy (2016). Ethical framework for the counselling professions. Leicestershire, UK: British Association for Counselling and Psychotherapy.

Butler AC, Chapman JE, Forman EM, Beck AT (2006). The empirical status of cognitive-behavioral therapy: a review of meta-analyses. Clinical Psychology Review 26, 17-31.

Carleton RN, Norton MA, Asmundson GJG (2007). Fearing the unknown: a short version of the Intolerance of Uncertainty Scale. Journal of Anxiety Disorders 21, 105-117.

Care Quality Commission (2013). Supporting Information and Guidance: Supporting Effective Clinical Supervision. Available at: http://www.cqc.org.uk/sites/default/files/documents/20130625_ 800734_v1_00_supporting_information-effective_clinical_supervision_for_publication.pdf (accessed 22 October 2014).

Dennhag I, Gibbons MBC, Barber JP, Gallop R, Crits-Christoph P (2012). Do supervisors and independent judges agree on evaluations of therapist adherence and competence in the treatment of cocaine dependence? Psychotherapy Research 22, 720-730.

Ellis MV, Ladany N (1997). Interferences concerning supervisees and clients in clinical supervision: an integrative review. In CE Watkins (ed), Handbook of Psychotherapy Supervision (pp. 447-507). New York, NY: Wiley.

Farrell NR, Deacon BJ, Dixon LJ, Lickel JJ (2013). Theory-based training strategies for modifying practitioner concerns about exposure therapy. Journal of Anxiety Disorders 27, 781787.

Gibbons CJ, Fournier JC, Stirman SW, DeRubeis RJ, Crits-Christoph P, Beck AT (2010). The clinical effectiveness of cognitive therapy for depression in an outpatient clinic. Journal of Affective Disorders 125, 169-176.

Gibbons CR, Stirman SW, DeRubeis RJ, Newman CF, Beck AT (2013). Research setting versus clinic setting: which produces better outcomes in cognitive therapy for depression? Cognitive Therapy Research 37, 605-612.

Gloaguen V, Cottraux J, Cucherat M, Blackburn I (1998). A meta-analysis of the effects of cognitive therapy in depressed patients. Journal of Affective Disorders 49, 59-72.

Gray-Little B, Williams VSL, Hancock TD (1997). An item response theory analysis of the Rosenberg Self-Esteem Scale. Personality and Social Psychology Bulletin 23, 443-451.

Hawkins P, Shohet R (1989). Supervision in the Helping Professions. Milton Keynes, UK: Open University Press.

Kadushin A (1976). Supervision in Social Work. New York, NY: Columbia University Press.

Kazdin AE (2008). Evidence-based treatment and practice: new opportunities to bridge clinical research and practice, enhance the knowledge base, and improve patient care. American Psychologist 63, 146159.

Kilminster SM, Jolly BC (2001). Effective supervision in clinical practice settings: a literature review. Medical Education 34, 827-840.

Lambert MJ, Ogles BM (1997). The effectiveness of psychotherapy supervision. In CE Watkins (ed), Handbook of Psychotherapy Supervision (pp. 421-446). New York, NY: Wiley. 
Leahy RL, Holland SJF, McGinn LK (2012). Treatment Plans and Interventions for Depression and Anxiety Disorders (2nd edn). New York, NY: Guilford Press.

Lilenfeld SO, Ritschel LA, Lynn SJ, Cautin RL, Latzman RD (2013). Why many clinical psychologists are resistant to evidence-based practice: root causes and constructive remedies. Clinical Psychology Review 33, 883-900.

Marcus M, Yasamy MT, van Ommeren M, Chisholm D, Saxena S (2012). Depression: A Global Crisis. Available at: http://wfmh.com/wp-content/uploads/2013/11/2012_wmhday_english.pdf

Mead DE (1990). Effective Supervision: A Task-Oriented Model for the Mental Health Professions. Philadelphia, PA: Brunner/Mazel.

Meyer JM, Farrell NR, Kemp JJ, Blakey SM, Deacon BJ (2014). Why do clinicians exclude anxious clients from exposure therapy? Behaviour Research and Therapy 54, 49-53.

Milne D, James I (2000). A systematic review of effective cognitive-behavioural supervision. British Journal of Clinical Psychology 39, 111-127.

Moldovan R, David D (2013). The impact of supervisor characteristics on trainee outcome in clinical supervision: a brief report. Journal of Cognitive and Behavioral Psychotherapie, 13, 517-527.

National Institute for Health and Care Excellence (NICE) (2011). Depression in adults (QS8). Available at: https://www.nice.org.uk/guidance/qs8 (accessed 10 October 2014).

Proctor B (1988). Supervision: a co-operative exercise in accountability. In M Marken and M Payne (eds), Enabling and Ensuring. Leicester, UK: National Youth Bureau and Council for Education and Training in Youth and Community Work.

Rosenberg M (1965). Society and the Adolescent Self-Image. Princeton, NJ: Princeton University Press.

Roth AD, Pilling S, Turner J (2010). Therapist training and supervision in clinical trials: implications for clinical practice. Behavioural and Cognitive Psychotherapy 38, 291-302.

Simpson-Southward C, Waller G, Hardy G (2016). Supervision for treatment of depression: an experimental study of the role of therapist gender and anxiety. Behaviour Research and Therapy 77, 17-22.

Stewart WF, Ricci JA, Chee E, Hahn SR, Morganstein D (2003). Cost of lost productive work time among US workers with depression. Journal of the American Medical Association 289, 31353144.

Stoltenberg CD, Delworth U (1987). Supervising Counselors and Therapists. San Francisco, CA: Jossey-Bass.

Tracey TJG, Bludworth J, Glidden-Tracey CE (2012). Are there parallel processes in psychotherapy supervision? An empirical examination. Psychotherap, 49, 330-343.

Turner H, Tatham M, Lant M, Mountford VA, Waller G (2014). Clinicians' concerns about delivering cognitive-behavioural therapy for eating disorders. Behaviour Research and Therapy 57, 38-42.

van Ooijen E (2000). Clinical Supervision: A Practical Guide. London, UK: Harcourt.

Waller G (2009). Evidence-based treatment and therapist drift. Behaviour Research and Therapy 47, 119-127.

Waller G, Mountford VA, Tatham M, Turner H, Gabriel C, Webber R (2013). Attitudes towards psychotherapy manuals among clinicians treating eating disorders. Behaviour Research and Therapy 51, 840-844.

Waller G, Stringer H, Meyer C (2012). What cognitive behavioral techniques do therapists report using when delivering cognitive behavioral therapy for the eating disorders? Journal of Consulting and Clinical Psychology 80, 171-175.

Wampold BE, Holloway EL (1997). Methodology, design, and evaluation in psychotherapy supervision research. In CE Watkins (ed), Handbook of Psychotherapy Supervision (pp. 11-27). New York, NY: Wiley.

Wang PS, Demler O, Kessler RC (2002). Adequacy of treatment for serious mental illness in the United States. American Journal of Public Health 92, 92-98. 
Weisz JR, Jensen-Doss A, Hawley KM (2006). Evidence-based youth psychotherapies versus usual clinical care: a meta-analysis of direct comparisons. American Psychologist 61, 671-689.

World Health Organisation (2012). Depression (Factsheet No. 369). Available at: http://www. who.int/mediacentre/factsheets/fs369/en/ (accessed 30 September 2014).

Worthington EL (1987). Changes in supervision as counselors and supervisors gain experience: a review. Professional Psychology 18, 189-208.

\section{Learning objectives}

(1) To explore the assumption that supervision contributes positively to therapy outcomes and helps keep therapy on track.

(2) To understand how a supervisor's own characteristics might affect patient outcomes.

(3) To consider the supervisor's role in therapist drift.

Appendix 1. Case vignettes used in the questionnaire

\begin{tabular}{|c|c|}
\hline Case type & Vignette \\
\hline Straightforward & $\begin{array}{l}\text { 'Mary is } 36 \text { and lives with her two children. She got divorced from her husband } \\
\text { two years ago, and currently has a partner of about four months. She has been } \\
\text { unhappy with life for approximately four years. In recent months, she has shown } \\
\text { more and more signs of depression, including a low mood and poor self-esteem, } \\
\text { though there are no biological signs. Although she is still doing her job in a } \\
\text { bakery, she is becoming increasingly socially isolated. She has given no } \\
\text { indication that she is suicidal. She was referred because of her low mood.' }\end{array}$ \\
\hline Diffuse & $\begin{array}{l}\text { 'Joanne is } 38 \text { and lives with her husband and son. She describes her relationship as } \\
\text { "solid", though she and her husband do not always get on well. She works as a } \\
\text { classroom assistant, though she would like to do something more challenging. } \\
\text { Her mood has generally been okay, but she reports feeling detached from the } \\
\text { world and feeling a lack of direction in her life. She finds herself feeling "down", } \\
\text { though would not harm herself. She sought a referral so that she would have } \\
\text { opportunity to talk about where she is going in life.' }\end{array}$ \\
\hline Complex & $\begin{array}{l}\text { 'Susan is } 35 \text {, and is currently in a relationship that she is unhappy with. } \\
\text { She is depressed and socially isolated. Her appetite and sleep are poor and she } \\
\text { reports feeling slowed down. She is struggling to find things funny or exciting } \\
\text { about life. These symptoms are affecting her ability to do her office job. She has } \\
\text { had suicidal ideas, but she is unsure whether she will act upon them, She recently } \\
\text { took a small overdose, though she described it as to help her "turn off" for a } \\
\text { while. That encouraged her to seek a referral for therapy.' }\end{array}$ \\
\hline
\end{tabular}

